\title{
O NOVO CÓDIGO DE PROCESSO CIVIL E A LEI DE MEDIAÇÃO: O INCENTIVO À CONSENSUALIDADE NA RESOLUÇÃO DE CONFLITOS ENVOLVENDO A ADMINISTRAÇÃO PÚBLICA
}

\author{
THE NEW CIVIL PROCESS CODE AND THE MEDIATION ACT: THE \\ INCENTIVE TO EXTRAJUDICIAL AND CONSENSUAL CONFLICTS \\ RESOLUTION IN PUBLIC ADMINISTRATION
}

\begin{abstract}
${ }^{1}$ Aline Sueli De Salles Santos
${ }^{2}$ Murilo Francisco Centeno

\section{RESUMO}

No contexto da consensualidade administrativa o presente artigo procura abordar aspectos do novo Código de Processo Civil e da Lei de Mediação que preveem a autocomposição de conflitos envolvendo a Administração Pública e determinam a criação de câmaras de mediação e conciliação dirigidas à resolução consensual e extrajudicial de conflitos naquele âmbito, enfocando, ainda, as perspectivas dessas inovações legislativas, que podem produzir resultados sociais relevantes.
\end{abstract}

Palavras-chave: Administração pública consensual, Novo código de processo civil, Lei de mediação

\begin{abstract}
The purpose of this paper is to discuss the contextual aspects of the norm, inserted in the article 174 of the New Civil Process Code and in the Mediation Act, which determines the creation of the chambers of mediation and conciliation, aiming to resolve the consensual and extrajudicial conflict in the public administration. In addition, it will also focuses on the perspectives of that legislative innovation, which tends to produce socially relevant results.
\end{abstract}

Keywords: Consensual public administration, New civil process code, Mediation act

\footnotetext{
${ }^{1}$ Doutora em Direito pela Universidade de Brasília - UnB, Brasília (Brasil). Professora adjunta da Universidade Federal do Tocantins - UFT, Tocantins (Brasil). E-mail: alinesalles@ uft.edu.br

${ }^{2}$ Mestrando em Prestação Jurisdicional e Direitos Humanos pela Universidade Federal do Tocantins - UFT, Tocantins (Brasil). E-mail: murilofcenteno@gmail.com
} 


\section{INTRODUÇÃO}

As diretrizes traçadas pelo novo Código de Processo Civil (CPC - Lei 13105, de 16 de março de 2015) refletem uma preocupação contemporânea voltada à remoção de entraves ou empecilhos prejudiciais à efetividade da jurisdição e à adequada solução dos conflitos de interesses instalados no seio social, ventilando a primazia do consenso na resolução das controvérsias.

Neste sentido, o novo diploma legal, cumulado com a Lei 13140, de 26 de junho de 2015 (Lei de Mediação), incentiva sobremaneira o emprego da autocomposição na resolução de conflitos, incluindo a Administração Pública no propósito de construção de uma cultura dialógica, a partir da determinação de criação de câmaras de mediação e conciliação destinadas a dirimir, no âmbito administrativo, os conflitos envolvendo os entes públicos - a exemplo do modelo existente na estrutura da Advocacia-Geral da União.

A iniciativa apresentada pela nova legislação é louvável, à medida que anela reduzir o excesso de litigiosidade ostentado por seu maior litigante, a Administração Pública, contribuindo para a desoneração do Poder Judiciário e o incremento de efetividade às decisões administrativas e judiciais.

Desta forma, a expressa (e dupla) previsão legal que permite a realização de acordos e transações como forma de proteger o interesse público (e não ao contrário, como se inferia da leitura burocrática sobre sua indisponibilidade) se insere em um movimento de consensualidade administrativa que se anuncia desde a reforma gerencial da década de 1990, podendo representar um instrumento chave para o desenvolvimento mais consistente desta forma de gestão pública.

É o que este estudo, de base bibliográfica e documental, procura analisar.

\section{A CULTURA DA LITIGIOSIDADE E A CRISE DO PODER JUDICIÁRIO}

É inegável que o Poder Judiciário tem sido impactado por um excessivo e crescente número de demandas, que reflete uma expressiva tendência de judicialização dos mais variados conflitos de interesses, constatada ao longo das últimas décadas.

O intenso exercício do direito de ação, demonstrado pela realidade sensível, reflete a ampliação do acesso à Justiça ${ }^{1}$, traduzindo, de igual modo e de certa forma, a conscientização 
dos partícipes da sociedade acerca de seus direitos subjetivos, bem como o natural anseio de afirmação concreta desses interesses juridicamente protegidos. Não obstante, o imenso volume de processos em curso nos diversos juízos e tribunais pátrios é também revelador de uma cultura de litigiosidade arraigada ${ }^{2}$ e até mesmo fomentada em nossa sociedade ${ }^{3}$, que prejudica o satisfatório funcionamento dos órgãos jurisdicionais, em prejuízo de toda a sociedade.

Com efeito, o grande congestionamento processual, somado a outros problemas sistêmicos, instalou verdadeira crise no Poder Judiciário, redundando na morosa solução das lides por meio de respostas ou decisões tardias e pouco efetivas, que não atendem prontamente às reais necessidades e aspirações dos jurisdicionados. ${ }^{4}$

Nesse contexto de intensa canalização de demandas aos órgãos jurisdicionais, também se inserem, com especial destaque, os entes que compõem as Administrações Públicas de todas as esferas governamentais, os quais sempre atuaram - frente aos conflitos em que figuram - de forma excessivamente litigiosa, intensificando a sobrecarga de processos em curso no Poder Judiciário, agravando a morosidade da jurisdição e contribuindo com a indesejável ineficácia do sistema.

É o que revela os relatórios do Conselho Nacional de Justiça (CNJ), "Justiça em números" ${ }^{\prime \prime}$, onde se vê que mais da metade das ações judiciais no Brasil referem-se a execuções fiscais, com alta taxa de congestionamento, evidenciando o quão dependente a Administração Pública ficou do Judiciário na solução de seus conflitos.

\footnotetext{
1 “A ampliação do acesso à Justiça, decorrente da Constituição Federal de 1988, impulsionou a proliferação de processos" (FARINELI; CAMBI, 2011, p. 278).

2 “...as pessoas de um modo geral, perderam a capacidade de superar suas adversidades, acomodando-se na entrega de seus litígios para serem resolvidos por um terceiro: a cultura do litígio, bem presente na sociedade contemporânea (CAHALI, 2012, p. 24). A par disso, "a concepção de que o Poder Judiciário é o único habilitado a solucionar conflitos sociais está difundida na sociedade. Com as ondas renovatórias de acesso à Justiça e, mais recentemente, com a expansão da Jurisdição Constitucional, os conflitos se judicializaram a ponto de o serviço jurisdicional centralizado não conseguir suprir, com rapidez e eficiência, as exigências constitucionais (art. 5, XXXV e LXXVIII, CF/1988)" (FARINELI; CAMBI, 2011, p. 278).

3 Ao longo dos anos, remanesceu patente a ausência de espaços institucionais voltados à conciliação e à mediação de conflitos sociais, assim como a carência de práticas efetivas de incentivo às soluções consensuais de litígios, que tenderiam a reservar ao Poder Judiciário apenas os casos não solucionados pelas vias alternativas de resolução de conflitos.

${ }^{4}$ A respeito da crise do Poder Judiciário, vejamos: "Inúmeras são as dificuldades enfrentadas por quem se dispõe a pleitear a jurisdição do Estado, na tentativa de obter proteção a um direito lesado ou ameaçado. A Justiça está em crise, não só no Brasil, como na maioria dos países. E crise na Justiça implica, necessariamente, Crise de Justiça. Os fatores que contribuem para esse estado de verdadeira calamidade podem ser resumidos basicamente na exagerada demora e no alto custo do processo" (BEDAQUE, 1998, p. 28-29). Ainda: "Suas decisões (...) são quase sempre respostas a posteriori das necessidades reais dos agentes sociais, portanto, incapazes de corresponder ao sentimento de justiça esperada do Poder Público" (BITTAR, 2009. p. 307).
} 
$\mathrm{Na}$ mesma linha, há diversos programas e ações do CNJ com vistas a uma desjudicialização de questões que envolvem o poder público, como aqueles ligados à própria conciliação e mediação, e outros tantos como o Fórum da Saúde e a Governança diferenciada de Execuções Fiscais. ${ }^{6}$

\title{
3 A NECESSÁRIA MODIFICAÇÃO DE PARADIGMAS
}

Com vistas à correção ou reversão de rumo, é de todo oportuno fomentar a adoção de técnicas consensuais e extrajudiciais de solução de controvérsias, buscando a prioritária pacificação social através da auto composição, que tende a recompor o tecido social de forma mais célere, desonerando a jurisdição estatal.

É preciso, pois, repensar os processos de pacificação, buscando a efetiva implementação de tendências que contribuam para a coesão social e o aprimoramento dos sistemas de justiça.

Nessa perspectiva, emergem a administração pública consensual, de um lado, e a conciliação e a mediação, de outro, de tal forma que ambas se prestam a construção participativa e dialógica dos interessados na gestão de seus interesses e à resolução consensual de litígios por atuação dos próprios envolvidos, ainda que auxiliados por interposta pessoa, contribuindo para a implantação de uma cultura de paz, vez que se voltam à busca de soluções harmônicas e efetivas em situações que envolvem múltiplos interesses.

\subsection{Administração pública consensual}

A transformação na Administração Pública impulsionada com a instituição do Estado Democrático de Direito e as reformas gerenciais iniciadas em meados da década de 1990 provocaram a emergência de um novo modelo para gestão pública denominada administração pública consensual, que sinaliza

\begin{abstract}
um novo caminho, no qual a Administração pública passa a valorizar (e por vezes privilegiar) uma forma de gestão cujas referências são o acordo, a negociação, a coordenação, a cooperação, a colaboração, a conciliação, a transação. Isso em setores e atividades preferencial ou exclusivamente reservados ao tradicional modo de administrar: a administração por via impositiva ou autoritária. (OLIVEIRA, SCHWANKA, 2008, p. 133)
\end{abstract}

\footnotetext{
${ }^{5}$ Estes dados se referem ao relatório do programa Justiça em números, realizado pelo CNJ, com o intuito de avaliar estatisticamente as despesas e produtividade no Judiciário Brasileiro. Tais informações estão disponíveis no site: http://www.cnj.jus.br/programas-e-acoes/pj-justica-em-numeros

${ }^{6}$ Disponível em: http://www.cnj.jus.br/programas-e-acoes?view=menunota
} 
Este novo modelo serve-se tanto de institutos jurídicos provenientes da esfera privada (contratualização, arbitragem), como de uma flexibilização do direito público estrito, formal, burocrático, para uma "atuação administrativa negociada, concertada, na qual o papel do administrado não se restringe a de mero destinatário do ato, mas a de coparticipante da atuação administrativa, sem, contudo, abandonar o regime jurídico público.” (BATISTA JUNIOR, CAMPOS, 2014, p. 35)

Neste sentido, a consensualidade na Administração encontra limites no interesse público, entendido tradicionalmente como indisponível. Ao analisar este princípio como óbice, Juliana de Palma (2010) defende que, posto que o referido princípio não tem base normativa, não impede manifestações de consensualidade administrativa, com exceção daquelas previstas em lei e de vinculação administrativa. E agora, com previsão legal expressa dos mecanismos de autocomposição e resolução consensual de conflitos, com maior razão, entende-se como promotores do interesse público.

\subsection{Conciliação e mediação}

Em linhas gerais, a conciliação expressa o mecanismo por meio do qual os envolvidos em uma contenda são auxiliados por um terceiro imparcial na definição de uma solução para o impasse. Com efeito, no âmbito da conciliação, as partes alcançam a resolução do litígio através de concessões recíprocas projetadas em uma solução acordada ou convencionada que melhor atenda aos seus interesses, conforme um cenário real de possibilidades.

A mediação, por sua vez, procura, através de interposta pessoa, restabelecer a comunicação rompida entra as partes, conduzindo os envolvidos no conflito à compreensão de suas divergências, ao entendimento dos fatores que a permeiam e à identificação de razões que conduzem à solução do litígio, como resultado de uma construção dos próprios mediados, pautada no diálogo cooperativo.

\footnotetext{
A mediação se assemelha à conciliação: os interessados utilizam a intermediação de um terceiro, particular, para chegarem à pacificação, de seu conflito. Distingue-se dela somente porque a conciliação busca sobretudo o acordo entre as partes, enquanto a mediação trabalha o conflito, surgindo o acordo como mera consequência (CINTRA, GRINOVER e DINAMARCO, 2014. p. 47).
}

É possível inferir dos contornos dos institutos que a atuação do conciliador é interventiva, comportando a apresentação de propostas, conselhos e sugestões de solução do conflito, ao passo que a atividade do mediador consiste, propriamente, na condução das partes 
à reflexão e interlocução acerca dos dissensos com vistas à construção do consenso, sem interferência direta na solução do conflito - que é elaborada pelos próprios interessados.

Sem prejuízo da distinção de métodos verificada na conciliação e na mediação, é inegável que ambas cumprem prestimoso papel, conduzindo à pacificação social operada à margem de uma solução judicial e impositiva. Traduzem, em última instância, valiosas ferramentas para a reversão das práticas desmedidas e desnecessárias de deflagração ou perpetuação de processos judiciais, refletindo paradigmas que, devidamente difundidos e dinamizados, tendem à factível reversão de uma cultura de litigiosidade.

\section{A CONCILIAÇÃO E A MEDIAÇÃo NO NOVO CÓDIGO DE PROCESSO CIVIL}

A Lei n. ${ }^{\circ}$ 13.105, de 16 de março de 2015, que institui o novel Código de Processo Civil, ventila ares de renovação ao sistema de justiça, pautando a solução dos conflitos pela primazia do consenso.

A propósito, o novo diploma legislativo, embora tenha por escopo precípuo regular o processamento das lides judiciais, institui um novo eixo central, que aponta para o caráter residual da resolução impositiva de litígios pelo Estado-Juiz, incentivando sobremaneira o emprego da conciliação e da mediação em qualquer fase das controvérsias.

Uma análise do texto legal, ainda que perfunctória, é suficiente para conduzir o leitor à conclusão de que as novas diretrizes normativas estimulam e favorecem o consenso na resolução das lides, em benefício da pacificação social e da correção dos problemas que assolam a jurisdição estatal.

Nesse viés, o Novo Código de Processo Civil, em seu artigo $3^{\circ}, \S 2^{\circ}$, proclama ser dever do Estado, de antemão, promover, tanto quanto possível, a solução consensual dos conflitos, ao tempo em que - no $§ 3^{\circ 8}$ do mesmo dispositivo - conclama os juízes, advogados, defensores públicos e membros do Ministério Público a estimularem, por dever de ofício, a conciliação, a mediação e outros métodos de resolução consensual das divergências sociais.

\footnotetext{
${ }^{7}$ Art. $3^{\circ}, \S 2^{\text {o }}$ O Estado promoverá, sempre que possível, a solução consensual dos conflitos.

8 Art. $3^{\circ}, \S 3^{\circ}$ A conciliação, a mediação e outros métodos de solução consensual de conflitos deverão ser estimulados por juízes, advogados, defensores públicos e membros do Ministério Público, inclusive no curso do processo judicial.
} 
Em seu artigo 165, a Lei Adjetiva orienta os tribunais pátrios a criarem unidades ou centros judiciários de solução consensual de litígios através da conciliação e da mediação, conforme as diretrizes que especifica, denotando, uma vez mais, a nova conformação ideológica da legislação, que procura estimular a pacificação social operada pela autocomposição. ${ }^{9}$

Prosseguindo na mesma esteira, o Novo Código Processual Civil assenta os princípios informativos da conciliação e mediação ${ }^{10}$, prevendo, outrossim, a manutenção de cadastro de conciliadores, mediadores e de câmaras privadas de solução consensual de conflitos por parte dos tribunais.

Ademais, no rito procedimental comum, foi instituída a audiência de conciliação e mediação, a ser realizada logo após a citação do réu, de forma antecedente ou preliminar à apresentação da contestação, conforme previsão contida no artigo 334 do novo diploma legal. ${ }^{11}$

Com efeito, é nitidamente perceptível que a nova legislação veicula um novo paradigma de resolução dos conflitos, com notórios estímulos à autocomposição, sem precedência semelhante no arcabouço normativo pátrio.

9 Art. 165. Os tribunais criarão centros judiciários de solução consensual de conflitos, responsáveis pela realização de sessões e audiências de conciliação e mediação e pelo desenvolvimento de programas destinados a auxiliar, orientar e estimular a autocomposição.

$\S 1$ 1o A composição e a organização dos centros serão definidas pelo respectivo tribunal, observadas as normas do Conselho Nacional de Justiça.

$\S 2$ o $\mathrm{O}$ conciliador, que atuará preferencialmente nos casos em que não houver vínculo anterior entre as partes, poderá sugerir soluções para o litígio, sendo vedada a utilização de qualquer tipo de constrangimento ou intimidação para que as partes conciliem.

$\S 3$ o $\mathrm{O}$ mediador, que atuará preferencialmente nos casos em que houver vínculo anterior entre as partes, auxiliará aos interessados a compreender as questões e os interesses em conflito, de modo que eles possam, pelo restabelecimento da comunicação, identificar, por si próprios, soluções consensuais que gerem benefícios mútuos.

${ }^{10}$ Art. 166. A conciliação e a mediação são informadas pelos princípios da independência, da imparcialidade, da autonomia da vontade, da confidencialidade, da oralidade, da informalidade e da decisão informada.

$\S 1^{\circ}$ A confidencialidade estende-se a todas as informações produzidas no curso do procedimento, cujo teor não poderá ser utilizado para fim diverso daquele previsto por expressa deliberação das partes.

$\S 2$ - Em razão do dever de sigilo, inerente às suas funções, o conciliador e o mediador, assim como os membros de suas equipes, não poderão divulgar ou depor acerca de fatos ou elementos oriundos da conciliação ou da mediação.

§ 3o Admite-se a aplicação de técnicas negociais, com o objetivo de proporcionar ambiente favorável à autocomposição.

$\S 4$ o A mediação e a conciliação serão regidas conforme a livre autonomia dos interessados, inclusive no que diz respeito à definição das regras procedimentais.

${ }^{11}$ Art. 334. Se a petição inicial preencher os requisitos essenciais e não for o caso de improcedência liminar do pedido, o juiz designará audiência de conciliação ou de mediação com antecedência mínima de 30 (trinta) dias, devendo ser citado o réu com pelo menos 20 (vinte) dias de antecedência. 
A par de todas as inovações postas, merece, porém, especial registro a previsão dirigida às Administrações Públicas quanto à instituição de câmaras de mediação e conciliação voltadas à solução consensual e extrajudicial de controvérsias envolvendo os entes públicos, nos termos do artigo 174, conforme veremos a seguir.

\section{AS CÂMARAS DE MEDIAÇÃO E CONCILIAÇÃO DAS ADMINISTRAÇÕES PÚBLICAS}

Em louvável iniciativa, o Novo Código de Processo Civil incluiu os entes federativos na política prioritária da conciliação e da mediação, dirigindo à União, aos Estados e Municípios um comando normativo voltado à instituição de câmaras administrativas de resolução consensual de seus conflitos. Vejamos:

\footnotetext{
Art. 174. A União, os Estados, o Distrito Federal e os Municípios criarão câmaras de mediação e conciliação, com atribuições relacionadas à solução consensual de conflitos no âmbito administrativo, tais como:

I - dirimir conflitos envolvendo órgãos e entidades da administração pública;

II - avaliar a admissibilidade dos pedidos de resolução de conflitos, por meio de conciliação, no âmbito da administração pública;

III - promover, quando couber, a celebração de termo de ajustamento de conduta.
}

\footnotetext{
$\S$ 1o O conciliador ou mediador, onde houver, atuará necessariamente na audiência de conciliação ou de mediação, observando o disposto neste Código, bem como as disposições da lei de organização judiciária.

$\S 2$ o Poderá haver mais de uma sessão destinada à conciliação e à mediação, não podendo exceder a 2 (dois) meses da data de realização da primeira sessão, desde que necessárias à composição das partes.

§ 3 o A intimação do autor para a audiência será feita na pessoa de seu advogado.

$\S 4$ ํ A audiência não será realizada:

I - se ambas as partes manifestarem, expressamente, desinteresse na composição consensual;

II - quando não se admitir a autocomposição.

§ 5o O autor deverá indicar, na petição inicial, seu desinteresse na autocomposição, e o réu deverá fazê-lo, por petição, apresentada com 10 (dez) dias de antecedência, contados da data da audiência.

$\S$ 6o Havendo litisconsórcio, o desinteresse na realização da audiência deve ser manifestado por todos os litisconsortes.

§ 7ำ A audiência de conciliação ou de mediação pode realizar-se por meio eletrônico, nos termos da lei.

$\S$ 8o O não comparecimento injustificado do autor ou do réu à audiência de conciliação é considerado ato atentatório à dignidade da justiça e será sancionado com multa de até dois por cento da vantagem econômica pretendida ou do valor da causa, revertida em favor da União ou do Estado.

$\S 9$ o As partes devem estar acompanhadas por seus advogados ou defensores públicos.

$\S 10$. A parte poderá constituir representante, por meio de procuração específica, com poderes para negociar e transigir.

$\S$ 11. A autocomposição obtida será reduzida a termo e homologada por sentença.

$\S 12$. A pauta das audiências de conciliação ou de mediação será organizada de modo a respeitar o intervalo mínimo de 20 (vinte) minutos entre o início de uma e o início da seguinte.
} 
A inovação é de todo oportuna e demonstra o efetivo intento legislativo de implementar medidas voltadas à concreta solução, ou ao menos amenização, dos problemas sistêmicos que, dinamizados ao longo dos tempos, comprometeram a eficácia dos sistemas vigentes de solução de controvérsias e pacificação social.

Dentre as bases que sustentam as novas diretrizes ideológicas de resolução de conflitos, repousa, por certo, a aspiração de reverter a incapacidade do Poder Judiciário de oferecer prontas respostas aos conflitos submetidos à sua apreciação, decorrente do excessivo número de demandas que lhe são confiadas. De tal sorte, a adoção de tendências inversas à judicialização de conflitos não poderia dispensar a inclusão, nesse circuito, dos entes que compõem a Administração Pública de todas as esferas governamentais, eis que, de um modo geral, o Poder Público se apresenta como um dos maiores litigantes, senão o maior deles, figurando como parte em milhares de processos em curso na jurisdição estatal.

O mecanismo em questão - posto a serviço da redução da litigiosidade dos entes públicos - tende a produzir resultados sociais relevantes, porém a provável confirmação de tal prognóstico dependerá do transcurso do tempo, assim como da mudança de posturas e da construção de uma nova cultura no âmbito da Administração Pública.

\section{A LEI DE MEDIAÇÃO}

$\mathrm{Na}$ esteira dos valores que inspiraram o novo CPC foi promulgada apenas alguns meses depois a Lei 13140/2015, denominada Lei de Mediação ${ }^{12}$.

Ali, a despeito do que já dispunha a lei processual, há dispositivos específicos sobre mediação judicial extrajudicial, a atividade e formação do mediador, bem como um capítulo sobre a "autocomposição de conflitos em que for parte pessoa jurídica de direito público" (art. 32 a 34 - disposições gerais; e 35 a 40 - no âmbito da administração federal).

Além de transcrever o art. 174 do novo CPC, a Lei de Mediação avança ao deixar clara a faculdade de, nos casos cabíveis, serem apresentados ou não às câmaras para a resolução consensual dos conflitos (art. 32, $\S 2^{\circ}$ ). Também indica a natureza de título extrajudicial que é dada ao acordo reduzido a termo, bem como a pertinência do uso das câmaras para questões envolvendo equilíbrio econômico-financeiro de contratos administrativos (art. 32, $\S 3^{\circ}$ e $\left.5^{\circ}\right)$.

${ }^{12}$ Apesar da sua promulgação depois da lei do novo CPC, a mesma já entrou em vigor em janeiro deste ano, depois de 180 dias de vacância, enquanto o CPC só iniciou sua vigência em março, 1 ano após a sua publicação oficial. 
Interessante também ressaltar a possibilidade da mediação ser utilizada de forma coletiva quando se tratar da prestação de serviços públicos (art. 33, p.u.), e a previsão de suspensão de prescrição quando da admissibilidade para instauração do procedimento administrativo, retroagindo à data da formalização do pedido (art. 34).

De tudo, o que mais importa destacar é a competência atribuída a cada ente federado para regulamentar sua câmara, de modo que, tanto a regulamentação trazida pela Lei de Mediação à câmara federal, como as normativas e experiências da mesma existentes até então, constituem-se em fontes importantes para que outras unidades da federação possam criar também seus órgãos e passar a exercitar a cultura de consenso e diálogo que essas iniciativas visam promover.

\section{A EXPERIÊNCIA DA ADMINISTRAÇÃo PÚbliCA FEDERAL: POSSÍVEL INSPIRAÇÃO DA NORMA CONTIDA NO ARTIGO 174 E MODELO ÚTIL À SUA IMPLANTAÇÃO}

Ao que parece, a previsão contida no artigo 174 do novo CPC, relativa à instituição das câmaras a que se refere, apresenta possível inspiração na experiência apresentada ao longo dos últimos oito anos pela Administração Pública Federal.

A propósito, em meio à tendência de amenização da cultura da litigiosidade, a União passou a instituir câmaras de conciliação e arbitragem $a d$ hoc frente a conflitos envolvendo órgãos da Administração Federal, os quais caso a caso, recomendavam a tentativa de resolução extrajudicial (BERNARDO, 2010, passim). ${ }^{13}$

A partir de resultados satisfatórios, colhidos no decorrer do exercício de 2007, foi então instituída, formal e permanentemente, no mesmo ano, a Câmara de Conciliação e Arbitragem da Administração Federal - $\mathrm{CCAF}^{14}$, como unidade integrante da ConsultoriaGeral da União - CGU, órgão de direção superior da Advocacia-Geral da União.

13 As Câmaras de Conciliação ad hoc eram instaladas com fulcro no artigo 11, parágrafo único da Medida Provisória n..$^{\circ}$ 2.180-35, de 24 de agosto de 2001, e na Portaria AGU n. ${ }^{\circ} 118$, de $1^{\circ}$ de fevereiro de 2007.

14 A Câmara de Conciliação e Arbitragem da Administração Federal - CCAF foi criada pelo Ato Regimental AGU n. ${ }^{\circ}$ 05, de 27 de setembro de 2007, e pela Portaria AGU n. ${ }^{\circ} 1.281$, baixada na mesma data. 
Inicialmente a sobredita câmara foi implantada para resolver, por meio de conciliação ou arbitramento $^{15}$, as controvérsias jurídicas existentes entre órgãos e entidades da Administração Pública Federal (BRASIL, 2012, p. 9). Não obstante, em momento temporal subsequente, suas atribuições foram ampliadas para abarcar - somente pela via da conciliação - as controvérsias jurídicas estabelecidas entre a Administração Pública Federal e as Administrações Públicas dos Estados e do Distrito Federal.

Posteriormente, o espectro de atuação da Câmara de Conciliação e Arbitragem da Administração Federal - CCAF experimentou novas ampliações, para também possibilitar, em um primeiro momento, tentativas de conciliação entre a Administração Pública Federal e os Municípios sedes das capitais dos Estados ou com mais de duzentos mil habitantes e, por fim, entre aquela e quaisquer Municípios, independentemente do quantitativo populacional destes (BRASIL, 2012, p. 9-10).

O procedimento conciliatório - no âmbito da câmara e conforme o caso - pode ser instaurado por solicitação: a) dos titulares ou dirigentes máximos dos órgãos ou entidades da Administração Pública Federal, assim como pelo Consultor-Geral da União, Procurador-Geral da Fazenda Nacional, Procurador-Geral Federal e Secretários-Gerais de Contencioso e de Consultoria; b) dos Governadores ou Procuradores-Gerais dos Estados e do Distrito Federal; c) dos Prefeitos ou Procuradores-Gerais de Municípios; d) em se tratando de conflitos judicializados, dos Ministros dos Tribunais Superiores e demais membros do Poder Judiciário, assim como dos órgãos de direção superior que atuam no contencioso judicial (BRASIL, 2012, p. 14-15).

As reuniões de conciliação são conduzidas por membros da Advocacia-Geral da União, que atuam na condição de conciliadores, funcionando como facilitadores de acordos ou consensos. A respeito do funcionamento das reuniões de conciliação e do papel dos conciliadores, convém consignar, in verbis:

\footnotetext{
15 Sobre esta arbitragem no âmbito da CCAF: “ARBITRAGEM: quando não ocorrer a conciliação, e somente nos casos envolvendo órgãos e entes da Administração Pública Federal, poderá ser proposto, ao Consultor-Geral da União, o arbitramento das controvérsias, que será feita por meio de parecer da Consultoria-Geral da União.” (BRASIL, 2012). E ainda: "A adesão à arbitragem não decorre, como se viu, de um ato que se possa caracterizar como próprio da autonomia privada. Na esfera pública, ao contrário prevalece o princípio da legalidade. Necessário dizer que os fundamentos dos atos praticados pela CCAF decorrem muito mais da Lei 9.784/1999, que regula o processo administrativo no âmbito da Administração Pública Federal e da LC 73/1993, Lei Orgânica da Advocacia-Geral da União, do que das Portarias e Decreto que servem, sobretudo, para disciplinar internamente os trâmites e procedimentos da CCAF, porém com eficácia infralegal." (SILVA, DALMAS, 2013, p. 
Na primeira reunião de conciliação, após a apresentação de todos os representantes, o Conciliador deverá esclarecer de forma sintética o procedimento conciliatório e a controvérsia jurídica. Após, é passada a palavra aos interessados, para suas manifestações. Ao final da reunião, é regido o Termo de Reunião, com a participação e a colaboração dos interessados, onde constarão sucintos registros das ocorrências e deliberações, com a indicação de tarefas, bem como seus responsáveis e prazos para o cumprimento, e ainda, se for o caso, com designação de data para próxima reunião. Este documento será assinado por todos os presentes, que o receberão digitalizado por e-mail.

Outrossim, se a controvérsia foi conciliada, será firmado o Termo de Conciliação.

[...]

O Conciliador atua como um facilitador do acordo, criando um contexto propício para o entendimento mútuo, aproximação dos interesses e harmonização das relações conflituosas. Assim, deve sempre buscar a melhor composição para a controvérsia jurídica e observar as seguintes premissas básicas: manter uma postura imparcial e adotar uma visão prospectiva da controvérsia; delimitar a controvérsia jurídica existente entre os interessados por meio de diálogo cooperativo - não de animosidade, e de efetiva participação - não de competição; propiciar uma análise multidisciplinar do conflito, a fim de reconhecer e articular os diversos fatores que componham a controvérsia; e, auxiliar na identificação dos interesses preponderantes para a solução do conflito" (BRASIL, 2012, p. 17-18).

Consoante se observa, embora denominada de Câmara de Conciliação e Arbitragem, é nitidamente perceptível que a CCAF desempenha não apenas técnicas de conciliação e arbitragem, mas também de mediação, buscando, dentro do possível, a construção do consenso entre as partes sob a lógica da cooperação e do diálogo por parte dos envolvidos. Deste modo, os intermediários da câmara atuam como indutores da harmonização das relações conflituosas, conforme se infere das atribuições do denominado conciliador, vertidas em linhas precedentes.

Nesse contexto, é possível concluir que o artigo 174 do novel CPC, ao preconizar a instituição de câmaras de mediação e conciliação no âmbito das Administrações Públicas pretende implementar, nas diversas esferas governamentais, mecanismos de resolução de controvérsias próximos ou assemelhados ao existente no âmbito da União, levando os intérpretes da norma à presunção de que a Câmara de Conciliação e Arbitragem da Administração Federal - CCAF tenha inspirado a referida construção legal. ${ }^{16}$

Contudo, ainda que assim não seja, é inegável que a experiência da Administração Pública Federal, que tem produzido resultados satisfatórios, pode servir de parâmetro para os demais entes da federação, representando um modelo passível de ser inicialmente replicado

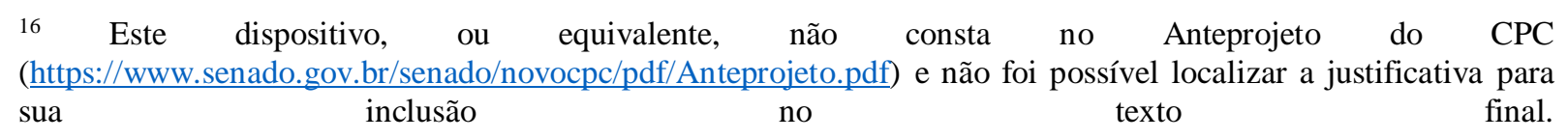


nos Estados e Municípios com vistas à concretização do disposto no aventado artigo 174, sem prejuízo de aprimoramentos imediatos ou posteriores - naturais e benéficos à evolução dos institutos e instituições.

Vale ressaltar que com o advento das disposições específicas da Lei de Mediação aplicada à Administração Federal, esse modo de resolução de conflitos entre seus entes deve ser obrigatoriamente tentado antes de autorização do Advogado-Geral da União para que haja ingresso de ação judicial, nos termos do art. 39.

Também se infere daquela lei a impossibilidade do uso dos mecanismos de resolução consensual de conflitos envolvendo tributos da Secretaria da Receita Federal ou créditos inscritos em dívida ativa (art. 38), salvo quando todos os envolvidos forem pessoas jurídicas de direito público federais, quando, reconhecido a existência de créditos, a AGU poderá solicitar diretamente ao Ministério do Planejamento, Orçamento e Gestão a devida adequação orçamentária para a quitação das dívidas (art. 36).

Sem dúvida o tema da mediação em matéria tributária é mesmo dos mais espinhosos no âmbito da administração consensual, mas não parece ser um impeditivo definitivo para que outros entes federados incluam essa possibilidade na esfera de competência de seus respectivos órgãos, uma vez que esta proibição foi alocado apenas na seção própria da administração federal.

\section{DIFICULDADES E RESULTADOS ESPERADOS}

O incentivo à solução consensual e extrajudicial de conflitos envolvendo os entes públicos, por meio do comando dirigido à implantação de câmaras de mediação e conciliação no âmbito das Administrações Públicas da União, dos Estados, do Distrito Federal e dos Municípios, tende a produzir resultados relevantes, em benefício dos entes federados, do sistema jurisdicional e, por conseguinte, da sociedade como um todo.

A obtenção de consensos no âmbito das câmaras promoverá a célere dissolução dos impasses ou resolução dos conflitos, residindo, nesse aspecto o primeiro benefício a ser considerado. Além da maior celeridade na solução da controvérsia, a resolução administrativa e consensual das divergências implica em consequente redução de gastos que seriam suportados pelos envolvidos e indiretamente pela sociedade com honorários profissionais, custas processuais, verbas de sucumbências e demais ônus previstos na legislação, a exemplo 
das verbas acessórias atinentes à evolução das dívidas de valor. Por fim, como a mais expressiva das contribuições ofertadas pelo sistema atinente às noticiadas câmaras, avulta a esperada redução do número de processos levados ao Poder Judiciário, como resultado da construção de uma cultura de consenso, pacificação e resolução extrajudicial de conflitos no âmbito dos Poderes Públicos (BERNARDO, 2010, passim).

Essa desoneração do Poder Judiciário milita em favor de sua eficácia e da maior efetividade das decisões judiciais, à medida que possibilita ou ao menos contribui com a fluidez das demandas que permanecerão reservadas à jurisdição, as quais tendem a experimentar tramitação e deslinde mais céleres ${ }^{17}$.

Há, no entanto, inúmeros desafios a serem enfrentados, em especial no que se refere à cultura burocrática, autoritária e unilateral da administração pública. Como alertou Ellen Gracie, a administração não costuma autorizar seus procuradores a transacionar direitos, nem mesmo para resolver a questão na esfera extrajudicial. “O x dessa questão é essa desconfiança com relação aos procuradores. Isso vai demandar uma mudança de mentalidade.” (apud SOUZA, 2015)

Neste sentido,

A cultura administrativa reinante [...] é a do medo, a do receio da punição. Não se tenta aperfeiçoar ou buscar a solução adequada, mas o receio enraizado aponta sempre para a solução de privilégio de uma interpretação literal dos regulamentos e ordens do hierarca. A eficiência administrativa e o bem comum são postos de lado em prol de uma atuação servil e, por vezes, medrosa e covarde.

Ou seja, não basta que haja a previsão de mecanismos legais para a autocomposição da administração pública, mas para que ele seja relevante e impacte na desjudicialização das relações administrativas é necessário efetivamente implementar uma cultura de consensualidade e diálogo que empodere os agentes públicos responsáveis e cative e dê confiança à sociedade para fazer uso desses meios.

\footnotetext{
${ }^{17}$ Não é demasiado lembrar que a aspiração geral a uma jurisdição ágil, capaz de garantir adequada celeridade aos processos judiciais, com tempestiva proteção e afirmação concreta da ordem jurídica e dos direitos porventura violados, é amplamente reconhecida como uma pretensão ética plausível e reivindicável por todos os cidadãos, independentemente de raça, cor, credo ou nacionalidade, configurando, pois, um direito básico, defendido em diversas nações do mundo contemporâneo e vertido para declarações ou tratados internacionais sobre direitos inerentes à condição humana, tais como a Convenção Americana sobre Direitos Humanos e a Convenção Européia para Salvaguarda dos Direitos do Homem e das Liberdades Fundamentais.

No Brasil, após a Emenda Constitucional n. ${ }^{\circ} 45 / 2004$, o aventado direito foi reafirmado com maior densidade por ocasião de sua inserção no rol dos direitos e garantias fundamentais previstos na Constituição da República, restando ora estampado no inciso LXXVIII do artigo $5^{\circ}$. Por força do referido dispositivo constitucional, "a todos, no âmbito judicial e administrativo, são assegurados a razoável duração do processo e os meios que garantam a celeridade de tramitação".
} 


\section{CONSIDERAÇÕES FINAIS}

À vista das razões postas, a política legislativa de inclusão dos entes públicos no circuito de construção de uma cultura de pacificação representa medida louvável, que merece o reconhecimento da comunidade jurídica e de toda a sociedade.

Por meio da concretização do artigo 174 do novo Código de Processo Civil e da Lei de Mediação, as Administrações Públicas, em todas as esferas da federação, terão espaços ou mecanismos institucionais estruturados que permitirão a resolução consensual e, sobretudo, extrajudicial de seus próprios conflitos, fomentando uma maior participação e autonomia da gestão pública, e, por via indireta, a celeridade na tramitação dos processos reservados à jurisdição, com significativa contribuição para a melhoria do sistema de justiça e da própria administração pública nacional.

\section{REFERÊNCIAS BIBLIOGRÁFICAS}

BATISTA JÚNIOR, Onofre Alves; CAMPOS, Sarah. A Administração Pública consensual na modernidade líquida. Fórum Administrativo - FA, Belo Horizonte, ano 14, n. 155, p. 31 43, jan. 2014.

BRASIL. Advocacia-Geral da União (AGU). Câmara de Conciliação e Arbitragem da Administração Federal - CCAF: cartilha. 3. ed. Brasília: AGU, Consultoria-Geral da União, 2012.

BEDAQUE, José Roberto dos Santos. Tutela cautelar e tutela antecipada: tutelas sumária e de urgência (tentativas de sistematização). São Paulo: Malheiros, 1998.

BERNARDO, Leandro Ferreira. A Câmara de Conciliação e o novo papel da AdvocaciaGeral da União. Revista da AGU. Brasília, n. 25, p. 163-184, jun./set. 2010.

BITTAR, Eduardo C. B. O direito na pós-modernidade e reflexões frankfurtianas. 2. ed. Rio de Janeiro: Forense Universitária, 2009.

CAHALI, Francisco José. Curso de arbitragem: resolução CNJ 125/2010: mediação e conciliação. 2. ed. São Paulo: Editora Revista dos Tribunais, 2012.

CINTRA, Antônio Carlos Araújo; DINAMARCO, Cândido Rangel e GRINOVER, Ada Pellegrini. Teoria geral do processo. 30. ed. São Paulo: Malheiros, 2014.

COELHO, Meire Lúcia Monteiro Mota; LÚCIO, Magda de Lima. Litigiosidade e Impacto na Gestão Pública - A mediação como instrumento de gestão - A experiência da Câmara de Conciliação e Arbitragem da Administração Federal. Revista da Procuradoria-Geral do Banco Central. Brasília, v. 4, n. 2. p. 75-97, dez. 2010. 
DIDIER JR., Fredie. Curso de direito processual civil: teoria geral do processo e processo de conhecimento. 6. ed. Salvador: JusPODIVM, 2006.

FARINELLI, Alisson; CAMBI, Eduardo. Conciliação e Mediação no Novo Código de Processo Civil (PLS 166/2010). Revista de processo. São Paulo: Revistas dos Tribunais, v. 36, n. 194, abr. 2011.

GUERRERO, Luis Fernando. Conciliação e mediação - Novo CPC e leis específicas. Revista de arbitragem e mediação. São Paulo: Revistas dos Tribunais, v. 11, n. 41, abr. 2014.

OLIVEIRA, Gustavo Justino de; SCHWANKA, Cristiane. A administração consensual como a nova face da Administração Pública no Séc. XXI: fundamentos dogmáticos, formas de expressão e instrumentos de ação. In: ANAIS DO ENCONTRO PREPARATÓRIO PARA O CONGRESSO NACIONAL DO CONPEDI, 17., 2008, Salvador, Anais... Salvador: 19, 20 e 21 jun. 2008.

SILVA, Eduardo Silva da; DALMAS, Samir Bahlis. Câmara de Arbitragem da AGU e Modelo Arbitral Brasileiro: Aproximações e Distinções. Revista de processo. São Paulo: Revistas dos Tribunais, v. 38, n. 217, mar. 2013.

PALMA, Juliana Bonacorsi de. Atuação Administrativa Consensual: Estudo dos Acordos Substitutivos no Processo Administrativo Sancionador. Dissertação de Mestrado, Universidade de São Paulo (Faculdade de Direito), 2010. 